\title{
ESTUDO SOBRE AS POSSIBILIDADES DE INTRUSÃO MARINHA NO AQÜIFERO BEBERIBE, REGIÃO COSTEIRA DE OLINDA-GOIANA (PE)*
}

\author{
EMÍLIO CUSTODIO**, WALDEMIR BARBOSA DA GRUZ***, \\ ADELBANI BRAZ DA SILVA***, FERNANDO GOMES JARDIM*** e \\ CARLOS ALBERTO DE MELLO PEIXOTO***
}

\begin{abstract}
The cretaceous sandstones of the Beberibe formation are the main aquifer of the seashore region Olinda-Goiana, State of Pernambuco. The low section corresponds to a semi-confined zone containing corrosive and soft waters while the upper section which is calciferous and partially recovered by a limestone formation, contains hard and more carbonated waters. As the water circulation in the confined zones tends to be nul under non influenced conditions and due to the existence of semi-impermeable sediments, in the vertical direction, there is no significant lateral escape towards the sea. This hydrogeochemical study indicates that there are no highly salinized waters in these zones, although the vertical eletrical soundings have indicated, along the seashore, very salinized waters at depth of 30-40 meters. The penetration of salty waters into the continent must be insignificant and limited to the superficial zone submitted to the influence of the tide; the salinity area is reduced to the channels and surroundings, being its influence rapidly limited laterally and vertically. Evidence of sea contamination only occurs in some wells of the intensively exploited area near Olinda, with the $\mathrm{rK} / \mathrm{rNa}$ ratio being very low and with positive $i t b$ values equal or superior to those of sea water. Because of the hydrodynamic characteristics of the aquifer, it seems to be unlikely that the salinity in these wells is due to the horizontal flow of the sea water or vertical descendent circulation through the "aquitard", since these processes occur at very slow rates. On the other hand, penetration of salty water along the well casing or the existence of preferential zones of vertical flows cannot be eliminated.
\end{abstract}

INTRODUÇÃo Um levantamento dos recursos hídricos subterrâneos, para fins de aproveitamento integrado, foi realizado pela SUDENE-GONESP, através da OESA, Organização e Engenharia S.A., na região costeira de Pernambuco, Paraíba e Rio Grande do Norte. Esses estudos, que se desenvolveram de junho de 1974 a março de 1976, compreenderam pesquisas a nível de detalhe, especialmente na região Olinda-Goiana, selecionada como uma das áreas de maior potencial hídrico subterrâneo de toda a região estudada (BEZERRA et al., 1970; SUDENE, GODESP, OESA, 1976).

Os referidos estudos tinham como objetivo definir as características dimensionais e hidrodinâmicas dos aqüíferos, as condições de circulação e descarga natural, o uso e produção atual da água subterrânea, a geoquímica das águas, além do estudo de possíveis influências de intrusão marinha.

Neste trabalho são apresentados os principais resultados referentes aos perigos de intrusão marinha a partir de uma explotação intensiva do aqüífero Beberibe, na faixa costeira.

*Estudo realizado pela SUDENE-DRN-CONESP, através da OESA, Organização e Engenharia S.A., como parte do programa "Estudos de Reconhecimento e Estudos Hidrogeológicos para Aproveitamento Integrado da Região Centro-Oriental da Bacia Potiguar e da Bacia Costeira de Pernambuco-Paraíba"

** Consultor da OESA e Diretor do Curso Internacional de Hidrologia Subterrânea, Beethoven, $15,3 .^{\circ}$, Barcelona, Espanha

***OESA, Organização e Engenharia S.A., Rio de Janeiro, Brasil 
Metodologia de trabalho As investigações hidrogeológicas envolveram uma série de procedimentos e métodos de avaliação dos recursos hídricos subterrâneos, incluindo:

- inventário hidrogeológico, compreendendo um levantamento de todos os pontos d'água existentes, abrangendo poços tubulares, poços manuais e fontes;

- medidas periódicas de níveis d'água em uma rede de poços de observação, para verificação das flutuações sazonais ou devidas às influências das marés;

- coleta e análise química das águas, tanto dos aquíferos profundos, como do freático e de águas superficiais;

- determinações dos conteúdos de radiocarbono e trítio das águas subterrâneas;

- perfuração de poços, sondagens e medidas com piezômetros para testes de aqüúfero e com objetivos estratigráficos;

- testes de aqüífero em poços existentes ou perfurados especialmente para o projeto, para determinação da capacidade de produção dos poços e das características hidrodinâmicas dos aqüíferos;

- levantamento geofísico a nível de reconhecimento pelo método de eletrorresistividade (sondagens elétricas).

GONDIÇÕES HIDROGEOLÓGICAS A bacia costeira de Pernambuco e Paraíba é constituída de uma seqüência de rochas sedimentares cretácicas, representada por uma formação basal arenítica (Formação Beberibe) e uma seqüência superior calcária (Formação Gramame). Sobre esses sedimentos ocorrem, em áreas restritas, uma formação calcária terciária (Formação Maria Farinha) e, em áreas extensivas, uma unidade terciária areno-argilosa (Grupo Barreiras) (Fig. 1) (BEURLEN, 1967; Mabesoone, 1967).

O principal sistema hidrogeológico da bacia é representado pela Formação Beberibe, uma sequiência de arenitos de granulação variável, contendo intercalações sílticas e argilosas na seção inferior e abundante cimento calcífero na parte superior. No conjunto, toda a seqüência pode ser considerada como um único sistema aqüífero, caracterizado por forte anisotropia e com permeabilidade vertical menor em relação à horizontal. Em detalhe e localmente, algumas particularidades, entre as seções inferior e superior, permitem caracterizar duas zonas aquiiferas: a correspondente à seção inferior, com arenitos normalmente friáveis, de granulação fina a grosseira, com intercalações finas e irregulares de siltitos e folhelhos e a zona aqüífera superior, correspondendo à pàrte superior da formação, constituída de arenitos duros, compactos, de granulação muito fina a média ou grosseira, contendo abundante cimento calcífero. As intercalações argilosas são mais raras e a rocha tem aspecto mais uniforme e maciço.

A zona aqüífera inferior pode ser definida como semiconfinada, limitada, na base, por um nível impermeável, representado pelo substrato cristalino pré-cambriano e, no topo, por uma camada ou nível semipermeável (folhelhos ou siltitos) que funciona como um aquitard. A zona aqüífera superior constitui, também, um aqüífero semiconfinado, separado do inferior por um aquitard, e se limita, no topo, pelos calcários da Formação Gramame ou pelos sedimentos do Grupo Barreiras.

A superfície do embasamento da bacia (Fig. 2) apresenta uma disposição muito uniforme e regular, com suave caimento em direção à costa. A inclinação geral dessa superfície varia de 20 a $35 \mathrm{~m} / \mathrm{km}$, com leve aumento de mergulho em direção ao mar e também ao sul, à medida que a bacia se estreita em direção à planície do Recife.

A Fig. 3 indica as espessuras saturadas dos níveis inferior e superior do aqüífero Beberibe. O mapa indica um progressivo espessamento do aqǘfero no sentido do oceano. $\mathrm{Na}$ borda da bacia, o aqüífero inferior apresenta espessuras a partir de $20 \mathrm{~m}$, enquanto na costa alcança de 160 a $180 \mathrm{~m}$. Ao sul, na área de Olinda, são registradas as maiores 


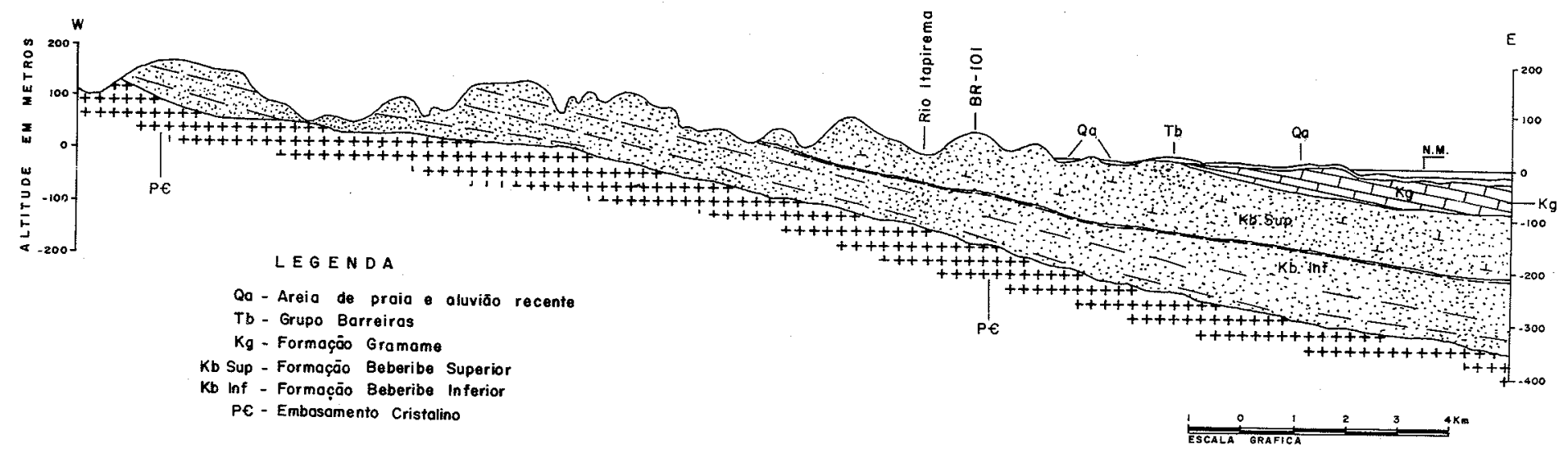

Figura 1 - Corte geológico transversal Barra de Catuama-Itapirema, Bacia Costeira de Pernambuco-Paraíba 


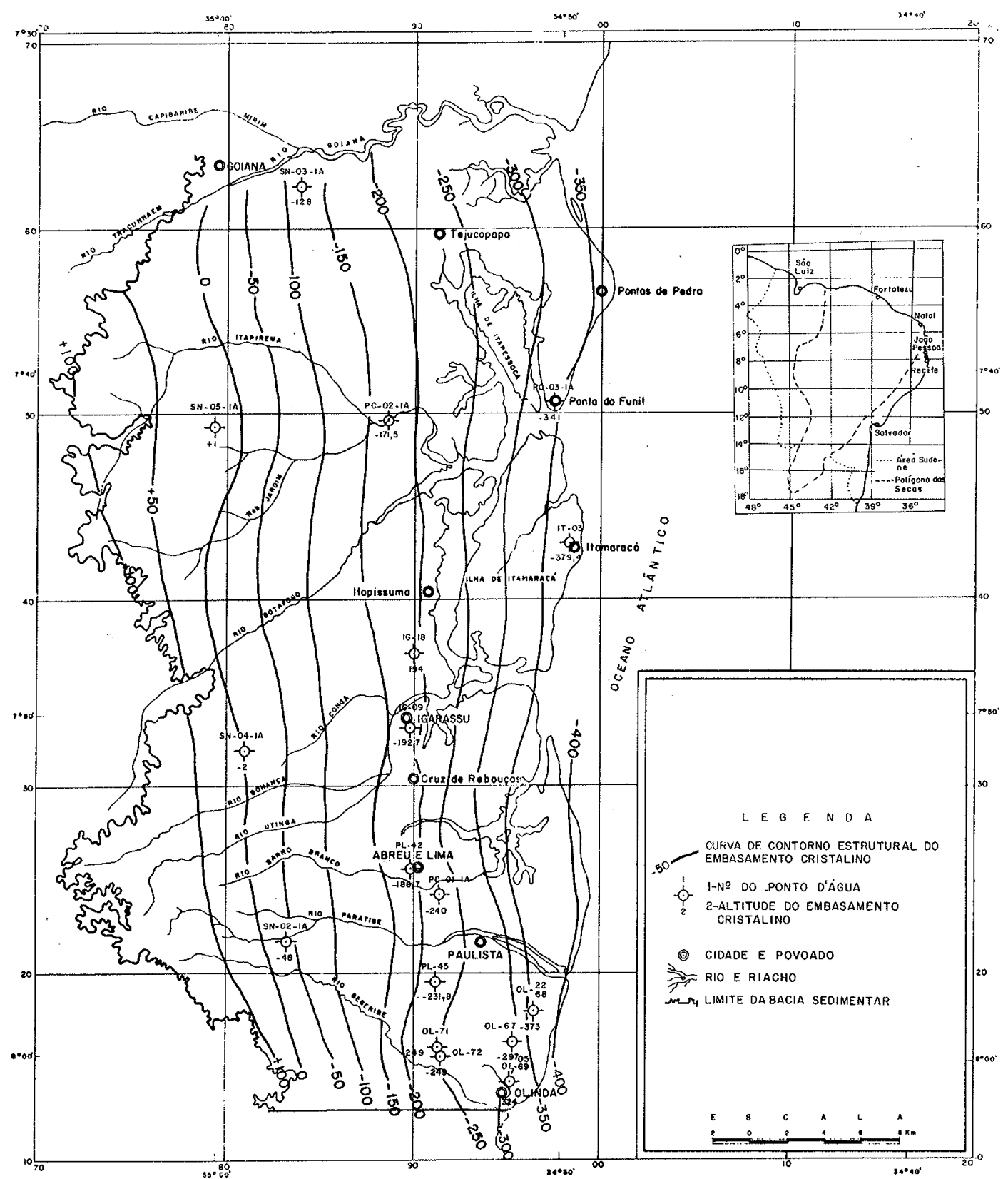

Figura 2 - Contorno estrutural da superficie do embasamento cristalino

espessuras, que podem atingir mais de $200 \mathrm{~m}$. O nível superior mostra, também, progressivo aumento de espessura desde seu limite oeste até a costa, onde atinge valores máximos da ordem de 140 m. A Fig. 4 mostra a disposição da superfície piezométrica dos aqüíferos inferior e superior da Formação Beberibe.

O mapa da superfície piezométrica, no aqüífero inferior, mostra as características destacadas a seguir. 


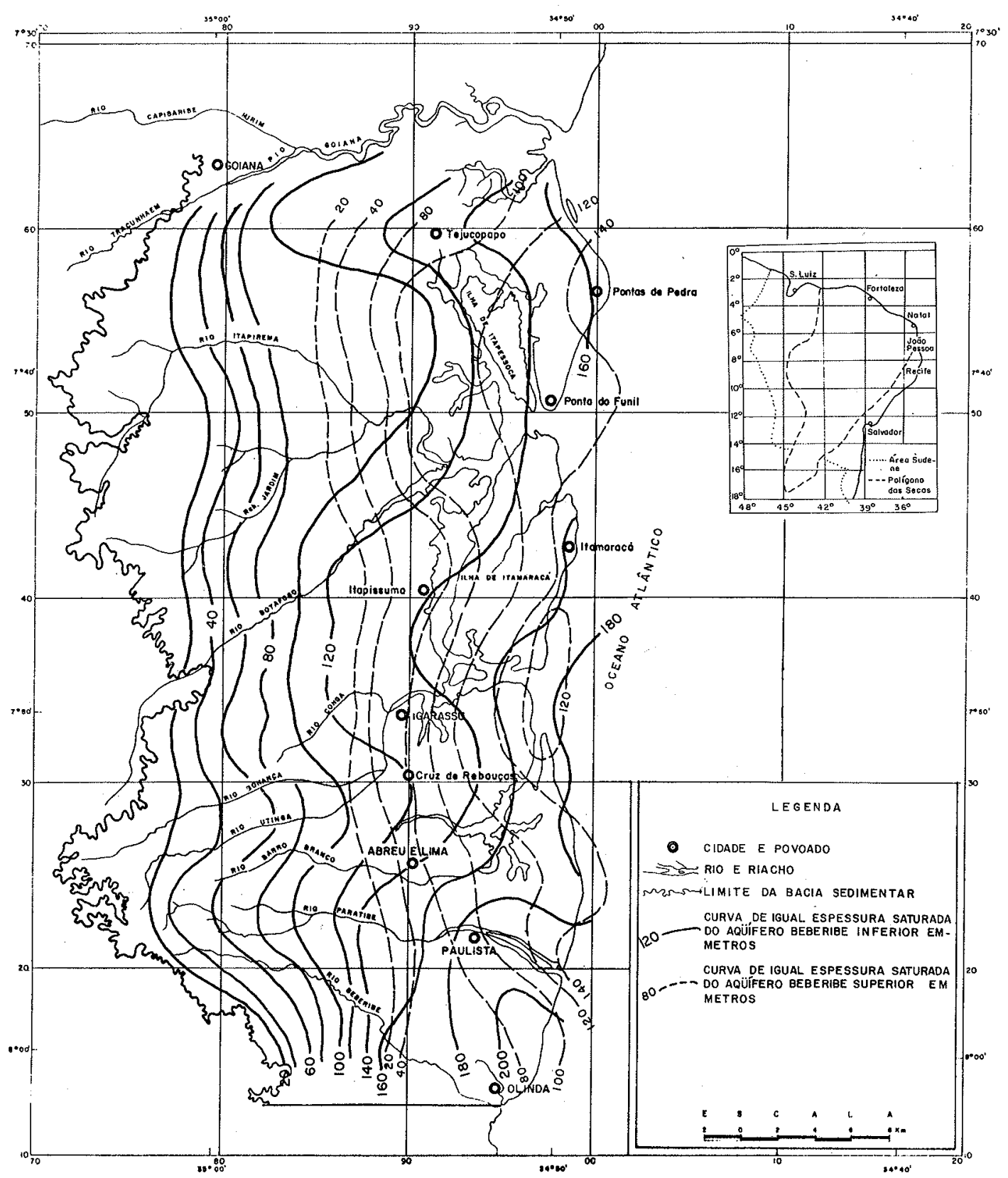

Figura 3 - Mapa de espessura saturada do aqüífero Beberibe inferior e superior

- Na área de recarga, a oeste, a superfície do lençol freático mostra um controle topográfico com linhas de fluxo convergentes em direção aos drenos superficiais. Os principais cursos d'água têm caráter efluente, ou seja, recebem contribuição das águas subterrâneas. Os gradientes hidráulicos são elevados, média de $7 \mathrm{~m} / \mathrm{km}$, com circulação rápida e grande volume de escoamento.

- A partir do limite onde o aqüífero passa a confinado, em direção ao mar, observa-se um sensível abrandamento dos gradientes hidráulicos que chegam a valores quase-nulos. 


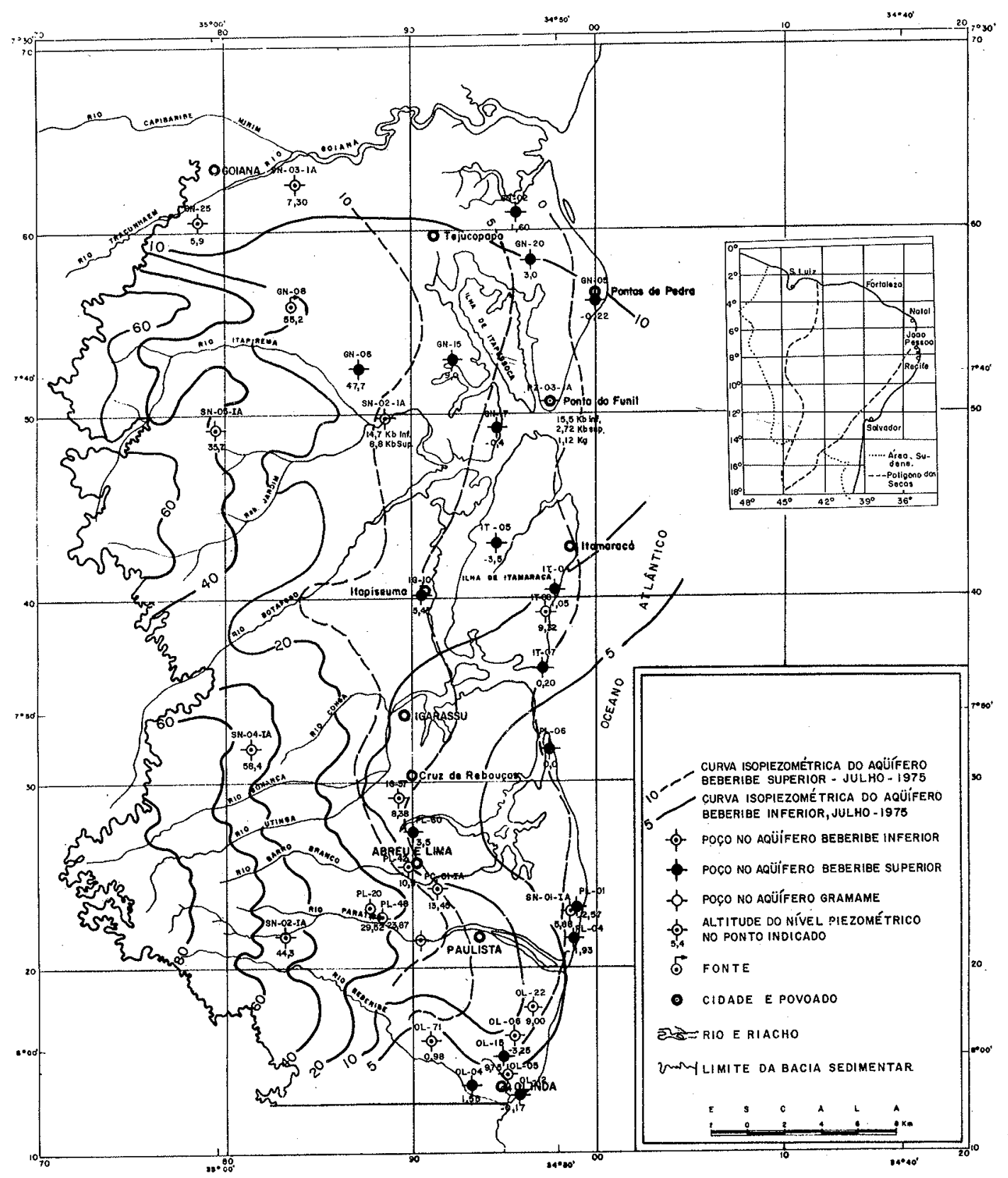

Figura 4 - Superfície piezométrica do aqüífero Beberibe superior e inferior

A circulação das águas subterrâneas tende a anular-se, em condições não-influenciadas. Essa condição de estancamento indica que não há significativa saída lateral em direção ao mar, provavelmente devido à presença de sedimentos pouco permeáveis.

- Na área de Olinda e Igarassu, a superfície piezométrica mostra acentuada inflexão, que parece relacionada aos efeitos de rebaixamentos regionais dos níveis d'água por efeito de bombeamento. A zona de maior concentração de bombeamento, neste aquífero, localiza-se nessá área. 
No aqüífero superior, o escoamento tem sentido geral para leste, com gradientes hidráulicos fracos, sendo notável a ocorrência de cotas negativas ou com valores próximos a zero, na faixa costeira, a partir de Maria Farinha até Olinda, indicando provavelmente influências de bombeamento na área. Embora as medidas de níveis d'água tenham sido efetuadas, em poços sem bombeamento ou que tenham sofrido paralização por alguns dias, é difícil verificar até que ponto essa superfície piezométrica se encontra influenciada por bombeamentos próximos. $\ddot{\mathrm{E}}$ possível que a superfície piezométrica, em condições estáticas, encontre-se um pouco mais elevada, mas, mesmo assim, com cotas próximas ao nível do mar, na costa.

Devido às condições de potencial piezométrico existentes e à presença do mar, os fluxos verticais devem predominar sobre os horizontais. A carga hidráulica do aqüífero superior é normalmente menor que a do inferior, devendo ocorrer trocas de água, entre os dois níveis, por filtração vertical através das camadas confinantes, se bem que se produzam em grande lentidão. $O$ mapa da Fig. 5 mostra a diferença de carga hidráulica entre os dois níveis. A quantidade de água fornecida por filtração vertical (leakage) do aquífero inferior para o superior foi calculada em $11,5 \times 10^{3} \mathrm{~m}^{3} / \mathrm{ano} / \mathrm{km}^{2}$.

A recarga do aquífero inferior tem lugar principalmente nas áreas de afloramento através de infiltrações de água de chuva. A maior parte das águas de infiltração é restituída aos rios e riachos que cortam a área de recarga e que funcionam como verdadeiros drenos. Devido às condições de circulação profunda no aqüífero, onde as águas se encontram praticamente estacionárias, somente pequena parcela dessas águas percolam em direção à zona confinada do aqüífero, para contrabalançar as perdas por filtração vertical e por bombeamento na área.

Medidas de descargas, efetuadas nos rios e riachos na área de recarga, no período de maio a novembro de 1975, e em correlação com os dados das bacias dos rios Gramame, Mumbaba e Mamoaba, que possuem período de observação de três anos, indicam que o volume das contribuições de água subterrânea restituído aos rios (escoamento subterrâneo) é de $368 \times 10^{6} \mathrm{~m}^{3} / \mathrm{ano}$, ou o equivalente a uma altura d'água da ordem de $600 \mathrm{~mm}$, o que corresponde a cerca de $35 \%$ da precipitação média anual sobre a área.

A quantidade de água que percola da área de recarga em direção à zona confinada do aquiúfero foi estimada, a partir das curvas isopiezométricas, em $14 \times 10^{6} \mathrm{~m}^{3} /$ ano. Esse volume é da mesma ordem de grandeza das perdas por leakage $\left(7,8 \times 10^{6} \mathrm{~m}^{3} / \mathrm{ano}\right)$ mais as saídas por bombeamentos que ocorreram entre julho de 1974 e julho de 1975 e estimados como da ordem de $6,5 \times 10^{6} \mathrm{~m}^{3}$.

Os dois níveis aqüíferos da Formação Beberibe sofrem influência das marés, em uma faixa próxima à costa. As hidrógrafas de níveis d'água dos poços descrevem uma curva sinusoidal, acompanhando o movimento harmônico simples do nível do mar. Os poços situados a uma distância superior a $2000 \mathrm{~m}$ da linha de praia, normalmente, não apresentam mais variações dos níveis d'água relacionadas à influência da maré. O Quadro I mostra os registros efetuados em poços de observação.

Os dados sobre as características hidrodinâmicas dos aqüíferos são apresentados no Quadro II. As determinações referentes à transmissibilidade do aquitard são ainda reduzidas e provêm de apenas três testes, dois realizados ao sul, em Olinda, e um ao norte, em Barra de Catuama.

A espessura e a continuidade lateral do aquitard são muito variáveis, podendo inclusive não ocorrer uma separação definida entre os dois níveis. Normalmente, entretanto, essas camadas são de reduzida espessura, variando de 5 a $15 \mathrm{~m}$. A permeabilidade, também, pode apresentar variações acentuadas, de uma área a outra, conforme indicam os perfis litológicos dos poços e os resultados de testes de aqüífero. Em Olinda, os perfis lito- 


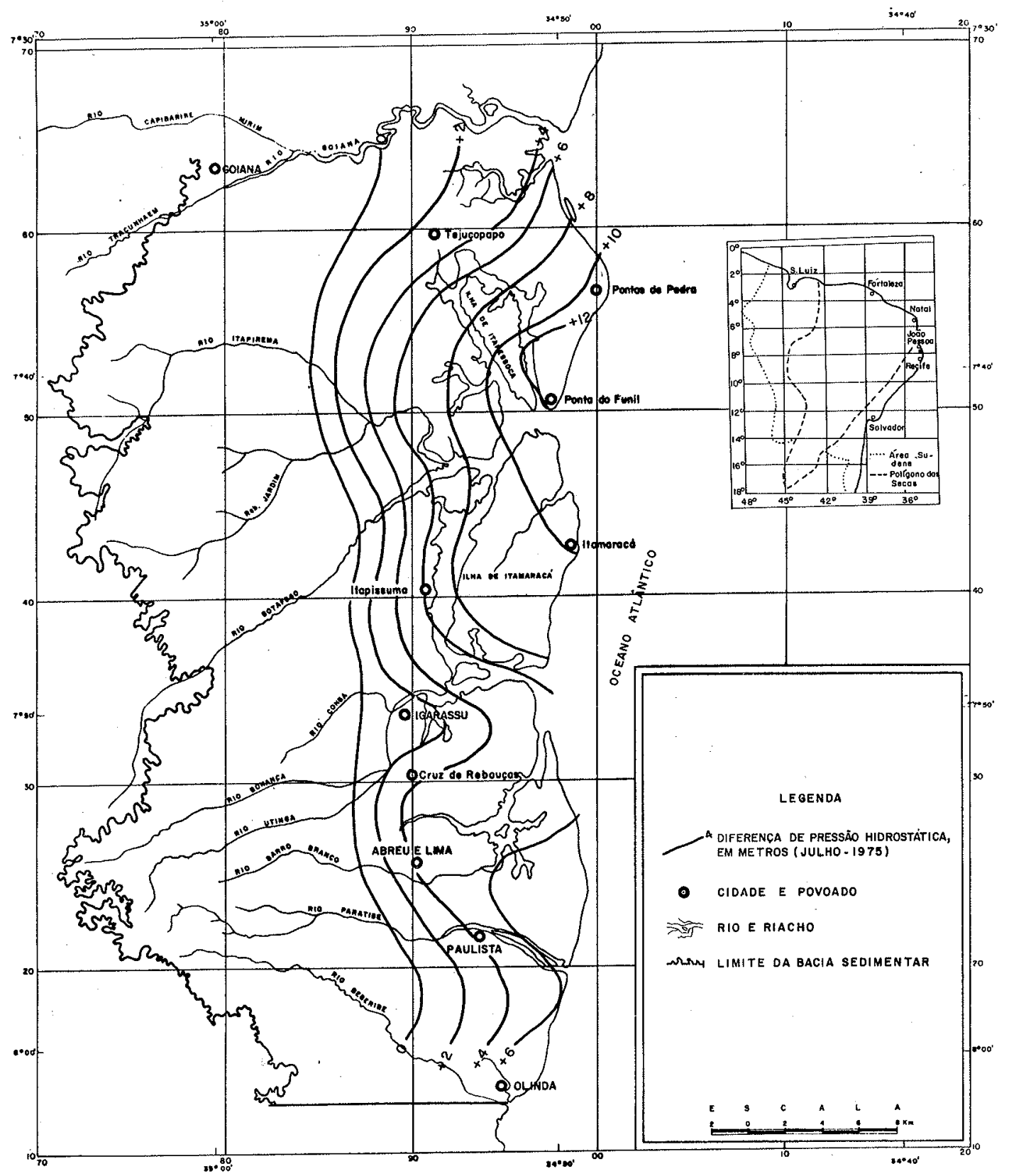

Figura 5 - Diferença de pressào hidrostática entre o aqüífero Beberibe superior e o inferior

lógicos mostram que o aquitard é constituído de $2 \mathrm{~m}$ de arenito finos, com intercalações de siltitos, enquanto, em outras áreas, como, por exemplo, em Barra de Catuama, Igarassu e Itamarácá, é representado por argilas ou folhelhos pouco arenosos e de baixa permeabilidade. Os testes realizados em Olinda e Barra do Catuama indicam o valor do coeficiente de permeabilidade do aquitard em $K^{\prime}=10^{-2}$ e $10^{-4} \mathrm{~m} /$ dia, respectivamente.

CONDIÇOES GEOIDROQUÍMICAS As águas do aqüífero Beberibe inferior são normalmente agressivas e pouco duras, na zona de recarga e média, e mantêm ainda 
Quadro I - Influência de maré nos poços da rede de observação periódica

\begin{tabular}{|c|c|c|c|c|c|c|c|c|c|}
\hline N. ${ }^{\circ}$ Poço & Localidade & Aqüífero & $\begin{array}{l}\text { Data das } \\
\text { medidas }\end{array}$ & $\begin{array}{l}\text { Período de } \\
\text { observação } \\
\text { (h) }\end{array}$ & $\begin{array}{c}h \\
(\mathrm{~m})\end{array}$ & $\begin{array}{c}x \\
(\mathrm{~m})\end{array}$ & $\begin{array}{l}h_{0} \\
(\mathrm{~m})\end{array}$ & 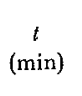 & $\begin{array}{c}C \\
(\%)\end{array}$ \\
\hline $\mathrm{OL}-12$ & Olinda & Kb Sup & $11 / 08 / 75$ & $9: 00$ & 0,0920 & 300 & 1,05 & 80 & 8,81 \\
\hline IT-04 & Itamaracá & Kb Sup & $19 / 08 / 75$ & $8: 30$ & 0,1250 & 250 & 0,85 & 30 & 14,70 \\
\hline OL-05 & Olinda & $\mathrm{Kb} \operatorname{Inf}$ & $18 / 08 / 75$ & $8: 00$ & 0,0095 & 1600 & 0,70 & $30(?)$ & 1,35 \\
\hline IT-07 & Itamaracá & Kb Sup & $14-15 / 08 / 75$ & $10: 30$ & 0,1500 & 250 & 0,55 & 28 & 27,20 \\
\hline PL-06 & Maria Farinha-Paulista & Kb Sup & $24 / 08 / 75$ & $8: 15$ & 0,1570 & 400 & 0,95 & 57 & 16,50 \\
\hline SN-01-IA & Janga-Paulista & $\mathrm{Kg}$ & $29 / 07 / 75$ & $12: 30$ & 0,0330 & 750 & 0,70 & 30 & 4,70 \\
\hline PL-04 & Janga-Paulista & Kb Sup & $12-28 / 05 / 75$ & $384: 00$ & - & 100 & - & - & 17,00 \\
\hline PZ-03-IA & Barra de Catuama-Goiana & $\mathrm{Kb} \operatorname{Inf}$ & $02 / 11 / 75$ & $11: 00$ & 0,2795 & 100 & 1,20 & 65 & 23,30 \\
\hline PZ-03-IA & Barra de Catuama-Goiana & Kb Sup & $02 / 11 / 75$ & $11: 00$ & 0,2450 & 100 & 1,20 & 65 & 20,40 \\
\hline GN-15 & - & Kb Sup & $13 / 08 / 75$ & $3: 30$ & 0,0000 & $5400(?)$ & - & - & 0,00 \\
\hline PZ-02-IA & Gambá-Goiana & Kb Sup & $09 / 06 / 75$ & $8: 30$ & 0,0000 & 6400 & 0,95 & - & 0,00 \\
\hline PZ-02-IA & Gambá-Goiana & $\mathrm{Kb} \operatorname{Inf}$ & $09 / 06 / 75$ & $8: 30$ & 0,0000 & 6400 & 0,95 & - & 0,00 \\
\hline SN-03-IA & Japumim-Goiana & $\mathrm{K} b \operatorname{Inf}$ & $20 / 08 / 75$ & $3: 30$ & 0,0000 & 13800 & - & - & 0,00 \\
\hline PG-0I-IA & Cafundó-Paulista & $\mathrm{Kb} \operatorname{Inf}$ & $12 / 08 / 75$ & $7: 30$ & 0,0000 & 7700 & 0,82 & - & 0,00 \\
\hline OL-04 & Olinda & Kb Sup & $11 / 08 / 75$ & $9: 15$ & - & 2400 & 1,05 & - & - \\
\hline
\end{tabular}

$h=$ subida ou descida da superfície piezométrica, com relação ao nível médio

$h_{0}=$ amplitude de onda ou a metade do intervalo de variação de maré

$x=$ distância do ponto de observação à linha da costa

$t=$ atraso de tempo de um dado máximo ou mínimo, após sua ocorrència no oceano

$C=$ eficiência aparente de maré - eficiência real de maré $\times$ coeficienut de amortização por afastamento da costa

Quadro II - Rcsumo clis características hidrodinâmicas dos aquíferos

\begin{tabular}{|c|c|c|c|c|c|c|c|c|c|c|c|c|c|}
\hline \multirow[t]{2}{*}{ Área } & \multirow[t]{2}{*}{ Aqüífero } & \multicolumn{3}{|c|}{$\begin{array}{c}\text { Coeficiente de } \\
\text { transmissividade, em } \\
\mathrm{m}^{2} / \text { dia }(T)\end{array}$} & \multicolumn{3}{|c|}{$\begin{array}{c}\text { Coeficiente de } \\
\text { permeabilidade, em } \\
\text { m/dia }(K)\end{array}$} & \multicolumn{3}{|c|}{$\begin{array}{c}\text { Coeficiente de } \\
\text { permeabilidade } \\
\text { vertical do aquitard, em } \\
\mathrm{m} / \mathrm{dia}\end{array}$} & \multicolumn{3}{|c|}{$\begin{array}{l}\text { Coeficiente de armazenamento } \\
\qquad(S)\end{array}$} \\
\hline & & MAX & MIN & MED & MAX & MIN & MED & MAX & MIN & MED & MAX & MIN & MED \\
\hline \multirow{3}{*}{$\begin{array}{l}\text { Olinda-Goiana } \\
\text { A-I }\end{array}$} & $\mathrm{Kg}$ & 66 & 60 & 62 & & & & & & & & & \\
\hline & Kb Sup & 275 & 25 & 165 & & & & & & & & & \\
\hline & Kb Inf & 490 & 15 & 170 & 3,6 & 0,1 & 1,6 & 0,06 & $1 \cdot 10^{-4}$ & 0,022 & $6,6 \cdot 10^{-3}$ & $5,8 \cdot 10^{-5}$ & $\begin{array}{l}1,15 \cdot 10 ? \\
2,8 \cdot 10 ?\end{array}$ \\
\hline
\end{tabular}

Abreviaturas:
MAX = valores máximos
$\mathrm{Kg}=$ Aqüífero Gramame
MIN = valores mínimos
$\mathrm{Kb}$ Sup $=$ Aqüífero Beberibe Superior
MED = valores médios
$\mathrm{Kb}$ Inf = Aqülfero Beberibe Inferior

certa agressividade no litoral, apesar do elevado tempo de contato com o aqüífero, indicador da ausência de carbonatos.

As águas do aqüífero Beberibe superior não são normalmente agressivas (podendo ser na parte mais baixa, porém não na parte alta), com um $\mathrm{pH}$ alto, conteúdo em $\mathrm{GO}_{2}$ dissolvido normal ou baixo e elevada dureza.

Existe, conseqüentemente, uma marcada estratificação química, com águas mais duras e carbonatadas, na parte superior do aqüífero, e com águas agressivas e freqüentemente menos duras, no inferior, o que exclui a existência de fluxos descendentes, mas não de fluxos ascendentes, pelo menos em condições naturais. Não obstante, o fluxo ascendente deve ser muito lento.

$O$ conteúdo de cloretos na água subterrânea (Fig. 6), na zona de recarga, varia normalmente entre 15 a 25 ppm e é similar à água dos rios que a drenam e que nascem na zona. Não se verifica nenhuma variação importante de cloretos com a profundidade.

Os conteúdos de sulfatos, mostrados na Fig. 7, indicam comportamento semelhante ao de cloretos, na zona de recarga, verificando-se somente que são de três a cinco vezes menor, em média, do que os de cloretos. 


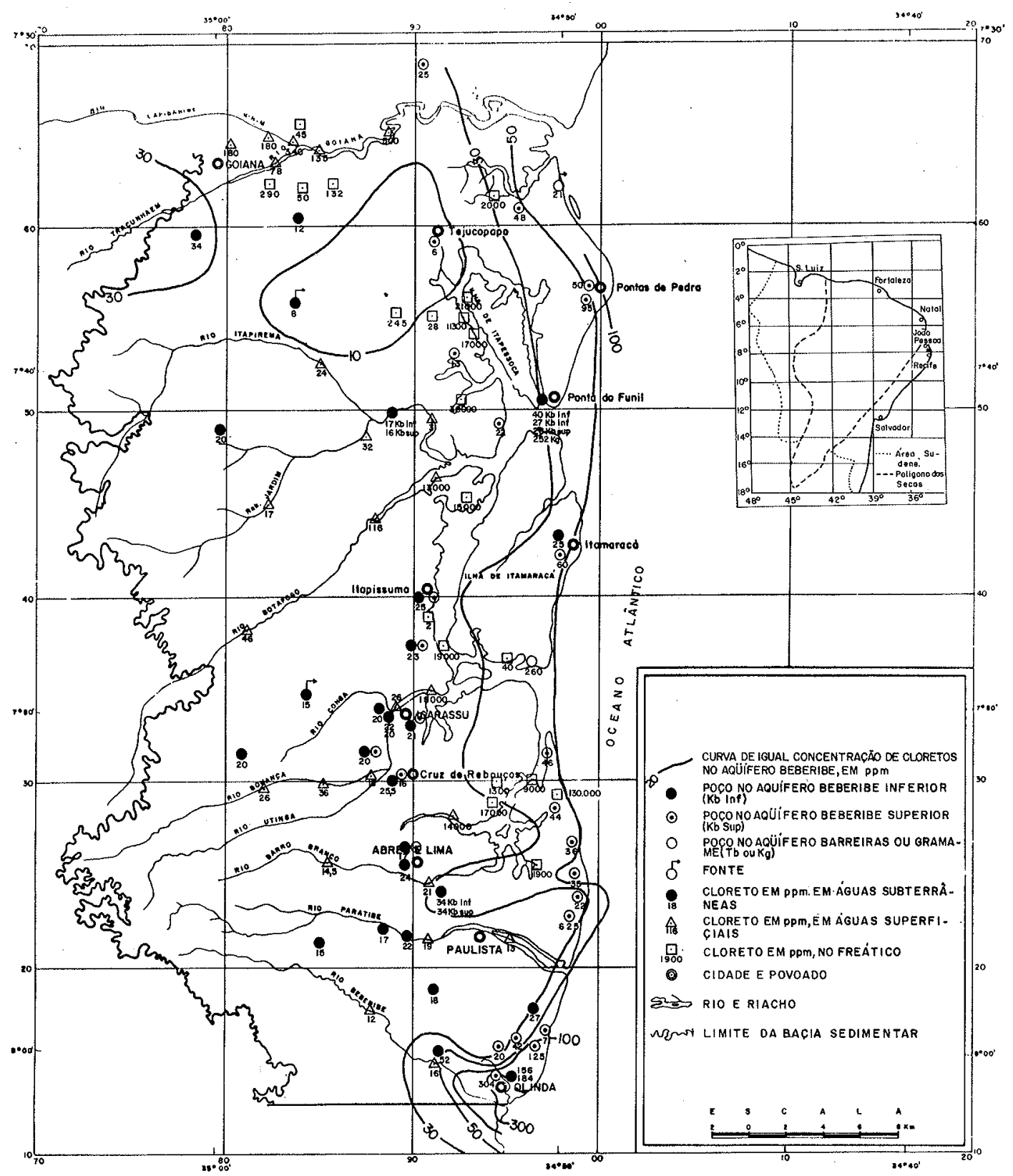

Figura 6 - Concentrações de cloreto nas águas superficiais e subterrâneas da área Olinda-Goiana

Analisando-se os dados de cloretos e sulfatos das Figs. 6 e 7, nada faz suspeitar que existam variações relevantes em sentido vertical, apesar da ausência de carbonatos na parte inferior e seu rápido aumento em direção ao teto. Nessas condições, parece razoável considerar que, aproximadamente, só existam variações no sentido horizontal, representadas pelo traçado das isolinhas das Figs. 6 e 7.

Ao passar da zona de recarga para a faixa costeira, o conteúdo de cloreto, que se situava ao redor de $20 \mathrm{ppm}$, inicia um lento crescimento, passando a $30 \mathrm{ppm}$ e alcançando 


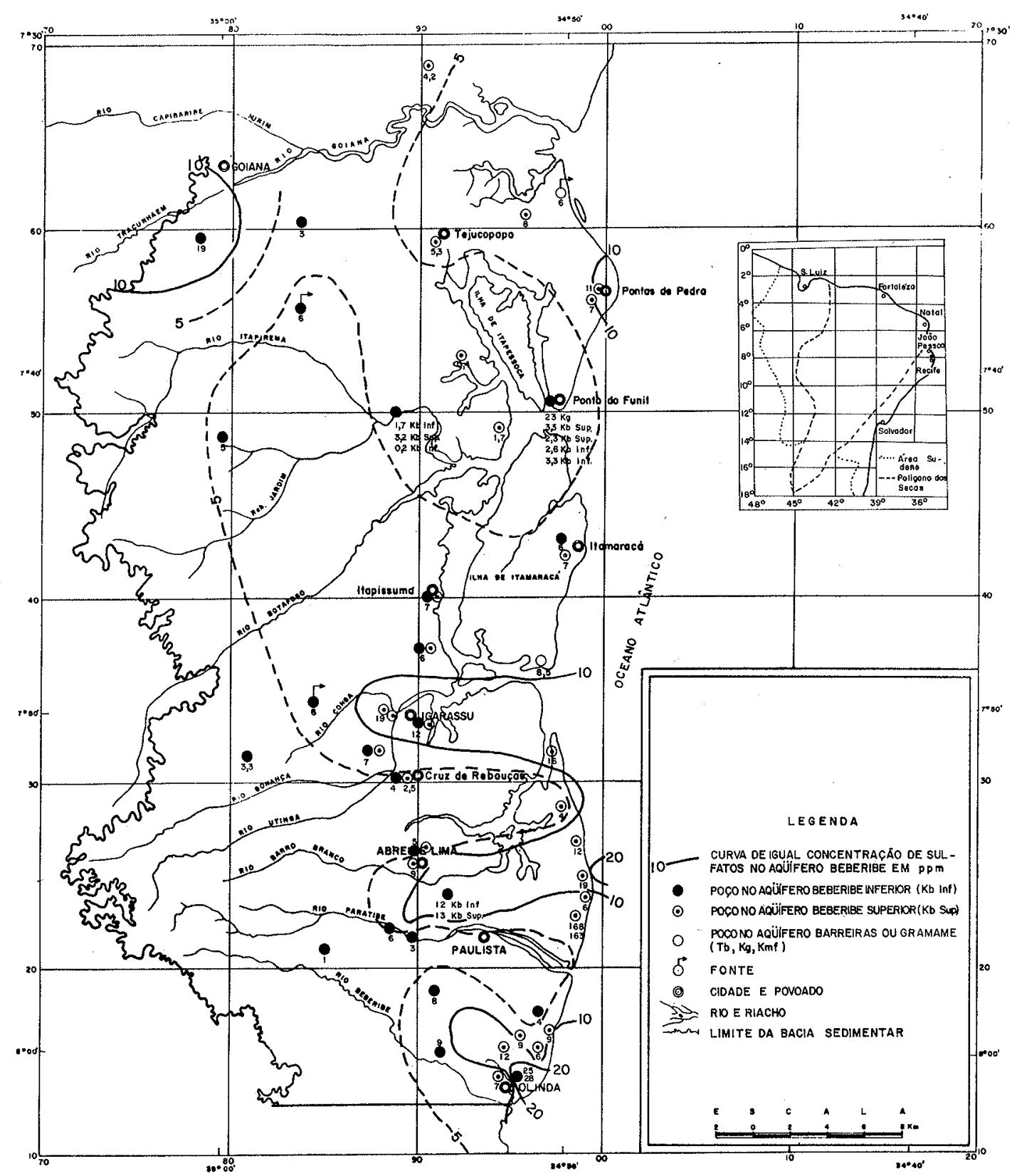

Figura 7 - Concentração de sulfato nas águas subterrâneas da área Olinda-Goiana

$50 \mathrm{ppm}$, no litoral. Quanto ao sulfato, apresenta, a grosso modo, um aumento desde 3-6 a 10-15 ppm. Em Olinda, por outro lado, existe um importante aumento localizado no conteúdo de cloreto, que afeta tanto a parte superficial como a profunda do aquífero Beberibe.

Com relação às variações da razão $r \mathrm{~K} / r \mathrm{Na}$ e do índice de troca de base $(i t b)$, merece destacar que as águas pouco profundas da faixa litoral indicam uma baixa relação $r \mathrm{~K} / r \mathrm{Na}$ e um valor positivo de $i t b$ correspondente a águas mais salinizadas e em relação com o 
Quadro III - Cloretos, razão $\mathrm{rK} / \mathrm{rNa}$ e índice de troca de base (itb), em amostras de água da área de Olinda

\begin{tabular}{llccc}
\hline Poço & Aqüífero & Cl em ppm & $r \mathrm{~K} / r \mathrm{Na}$ & itb \\
\hline \hline OL-11 & Kb Sup & 125,0 & 0,14 & $+0,50$ \\
OL-14 & Kb Sup & 304,0 & 0,05 & $+0,61$ \\
OL-69 & Kb Inf & 169,0 & 0,06 & $+0,24$ \\
\hline
\end{tabular}

$\operatorname{mar}(r \mathrm{~K} / r \mathrm{Na}=0,015 ; i t b=+0,12)$. O fato do valor de $i t b$ ser igual ou superior ao marinho indica um equilíbrio ou uma possível tendência à salinização (Gustódio, 1976), posto que existe um intercâmbio de $\mathrm{Na}$ por $\mathrm{Ca}$ e $\mathrm{Mg}$ (Quadro III).

Quanto às águas subterrâneas menos profundas, principalmente as do calcário Gramame, os dados são muito escassos e assinalam águas já bastante cloretadas, perto do mar, com um conteúdo em sulfatos de tendência elevada, porém sem que possam ser consideradas águas salgadas. Os poços profundos, nessa formação, penetram até sua base, não havendo dados das zonas média e alta.

Podem ser esperadas, todavia, salinidades elevadas, conforme evidenciado pelo reconhecimento geofísico (Feitosa, 1976) que indicou:

Ponta do Funil - salinizados os primeiros $25 \mathrm{~m}$;

Itamaracá - salinizados os primeiros $25 \mathrm{~m}$;

Olinda-Paulista - salinizados os primeiros $40 \mathrm{~m}$;

Zona entre Olinda e Recife, um pouco afastada do litoral - salinização moderada até $30 \mathrm{~m}$ de profundidade.

Nos três primeiros locais, a resistividade chega a decrescer até $3 \Omega \cdot \mathrm{m}$, o que assinala a presença quase-inequívoca de água marinha, especialmente tendo em conta que se trata de materiais calcários e arenosos.

Além das águas notadamente salinas e de caráter cloretado-sódico das formações superiores, só aparecem sinais de contaminação marinha na área de Olinda, principalmente nos poços OL-14 e OL-69. O primeiro destes é parcialmente penetrante e tem filtros entre 80 e $110 \mathrm{~m}$ de profundidade, justamente no teto das areias cimentadas da parte superior Formação Beberibe. O segundo tem seção de filtros entre 180 a $330 \mathrm{~m}$, desde a parte média até a profunda da Formação Beberibe. A esses poços e ao OL-11, próximo e também relativamente salinizado, correspondem valores muito elevados de $i t b$, que superam amplamente o valor da água marinha $(+0,12)$, o que identifica alguma forma de penetração de águas salgadas.

CONTAMINAÇÃO MARINHA ATUAL O estudo hidrogeoquímico realizado indica que não se encontram águas fortemente salinizadas na zona, embora o reconhecimento geofísico de superfície (sondagens elétricas verticais) (Feitosa, 1976), indique, no litoral, águas muito salgadas até algumas dezenas de metros de profundidade, de acordo com uma situação de caráter normal. A existência de um potencial hidráulico, crescente em profundidade, impede a existênicia de águas salgadas mais abaixo.

Essa rápida diminuição da salinidade, em profundidade, aparece nos calcários da Formação Gramame $(\mathrm{Kg})$, como mostra o piezômetro menos profunda da sondagem PZ-03-IA $(\simeq 30 \mathrm{~m})$, com somente $250 \mathrm{ppm}$ de $\mathrm{Cl}$, enquanto que a geofísica indica água marinha até cerca de $25 \mathrm{~m}$. O mesmo sucede com a sondagem SN-01-IA, com tela entre 42 e $78 \mathrm{~m}$ e água de $625 \mathrm{ppm}$ de $\mathrm{Cl}$, para o poço IT-07, perfurado até $116 \mathrm{~m}$ e revestido deficientemente $(\mathrm{Gl}=260 \mathrm{ppm})$. 
A penetração da água salgada no continente deve ser muito pequena e, na área superficial submetida à influência de maré, a salinidade se reduz aos próprios canais e zonas imediatas, ficando rapidamente limitada lateral e verticalmente.

Em Ponta do Funil, na parte inferior do aqüífero Beberibe (Kb Inf), a cota do nível piezométrico é $15,5 \mathrm{~m}$, praticamente horizontal (gradiente menor que $10^{-4}$ ). Esse nível permite equilibrar uma coluna de água de $15,5 \times 40=620 \mathrm{~m}$ e, com um mergulho do embasamento cristalino de $18 \times 10^{-3}$ e uma profundidade do mesmo de $340 \mathrm{~m}$ na sondagem, o contato teórico com a água marinha se verificaria a uma distância de $15 \mathrm{~km}$ mar adentro. Sem dúvida, dado que o fluxo é praticamente estacionário, a zona de transição pode ser muito espessa e iniciar, já, desde o próprio litoral, com um aumento de cloreto muito lento, porém contínuo.

Nesse mesmo local, um piezômetro de $180 \mathrm{~m}$ de profundidade, com água doce, tem a cota do nível piezométrico de $2,7 \mathrm{~m}$ e a superfície piezométrica indica que existe fluxo horizontal. A profundidade teórica da interface, em regime estacionário, seria de $108 \mathrm{~m}$, notadamente menor que a do filtro. Possivelmente, o piezômetro está afetado pelos bombeamentos da zona e a cota de seu nível estático devia ser maior, talvez da ordem de 5 ou $6 \mathrm{~m}$, de acordo com dados de outro piezômetro, com um gradiente piezométrico menor que o atualmentemente assinalado pelo mapa piezométrico.

Nessas condições, a interface teórica estaria afastada da zona de filtro, porém não excessivamente. A situação atual é semelhante ao longo de toda a costa, para a parte superior do aqüífero Beberibe (Kb Sup), mais acentuada quanto mais ao Sul, onde os bombeamentos são mais intensos. A existência do aqüífero Gramame (Kg) e de intercalações argilosas dificultam a intrusão da água marinha no momento, embora esta parte do aquífero esteja pior protegida que os níveis profundos ( $\mathrm{Kb}$ Inf), resguardados pelas intercalações argilosas mais profundas, que são mais espessas e, talvez, de maior continuidade.

Possiveis sinais de contaminação marinha somente ocorrem nos poços profundos, litorais, e em alguns dos poços da área intensivamente explorada de Olinda, em especial os denominados OL-14 (Kb Sup), OL-69 (Kb Inf) e OL-11 (Kb Sup). Infelizmente, é desconhecida a qualidade inicial da água destes poços e não é segura a existência de uma salinidade progressiva.

Tal como foi indicado, é difícil identificar o mecanismo de salinização, que exigirá o prosseguimento dos estudos de detalhe da zona e, possivelmente, alguma sondagem de reconhecimento.

Nos aquíferos profundos, observa-se um ligeiro incremento da salinidade em direção o litoral. Este se torna cada vez mais rápido, à medida que a velocidade vai diminuindo. Isso quer dizer que, do litoral para o mar, a salinidade deve crescer, até serem alcançados, possivelmente, valores correspondentes à água marinha.

Pode, assim, pensar-se que a salinização seja um efeito de movimento lateral dessas águas mais salgadas, contidas no aquiúfero no lado do mar, misturadas com as águas procedentes do continente. $\mathrm{O}$ movimento seria rápido inicialmente, devido a efeitos de descompressão elástica, e logo iria diminuindo, à medida que os níveis evoluíssem para uma situação estacionária, mantida pela recarga no afloramento. Não obstante, é necessário que sejam feitos alguns cálculos, para confirmar tal possibilidade.

A recarga efetiva do aqǘfero Beberibe, por dia e por metro da costa, é da ordem de $10 \mathrm{~m}^{3} / \mathrm{dia} / \mathrm{m}$. Supondo-se uma exploração costeira equivalente a $5 \mathrm{~m}^{3} / \mathrm{dia} / \mathrm{m}$, com $T=50 \mathrm{~m}^{3} /$ dia e $S=10^{-2}$, o tempo para a depressão de bombeamento alcançar a área de recarga, considerada a uma distância efetiva de $10 \mathrm{~km}$ pode ser deduzido, para poços em aquíferos confinados e em regime não-permanente, à vazão constante, das seguintes 
fórmulas :

onde

$$
s=\frac{q x}{2 T} D(u) \quad u=\frac{S x^{2}}{4 T t}
$$

$$
\begin{aligned}
s & =\text { rebaixamento; } \\
q & =\text { vazão por unidade de comprimento; } \\
T & =\text { transmissibilidade; } \\
D & =\text { função de poço a vazão constante; } \\
S & =\text { coeficiente de armazenamento; } \\
x & =\text { distância normal ao poço; } \\
t & =\text { tempo. }
\end{aligned}
$$

Para um valor, no limite de recarga, de $s=0,1 \mathrm{~m}$, têm-se

$$
\begin{aligned}
D(u) & =\frac{0,1 \times 2 \times 50}{5 \times 10^{4}}=2 \times 10^{-4}, \\
u & \simeq 2, \\
t & =\frac{10^{-4} \times 10^{8}}{4 \times 50 \times 2}=25 \text { dias. }
\end{aligned}
$$

O valor de $t$ obtido é pouco sensível ao valor adotado de $s$, no limite de recarga. Entretanto o valor de $S$ é muito mais sensível, de modo que, para $S=10^{-3}, t=250$ dias. Tomando $t=100$ dias, nesse tempo teria sido extraído: $100 \times 10=1000 \mathrm{~m}^{3} / \mathrm{m}$ por cada lado, ou seja, $500 \mathrm{~m}^{3} / \mathrm{m}$ do lado do mar.

O movimento horizontal da água, para uma porosidade de 0,1 e uma espessura de $100 \mathrm{~m}$, é

$$
d=\frac{500}{100} \times \frac{1}{0,1}=50 \mathrm{~m}
$$

que é muito pouco e portanto não pode explicar o aumento de cloretos, nas áreas de bombeamento, por simples deslocamento horizontal de águas mais salinas para o mar, por causa de simples fenômenos elásticos. Em todo caso, deve ser admitida uma certa recarga.

Um deslocamento de $1 \mathrm{~km}$, em 10 anos, supõe um gradiente piezométrico de

$$
\begin{aligned}
& v=\frac{k}{m} i, \\
& i=\frac{\frac{1000}{10 \times 365} \times 0,1}{50 / 100}=0,055=55 \times 10^{-3},
\end{aligned}
$$

que é excessivamente elevado e está em total discordância com as salinizações observadas. Esse valor também indica que o mecanismo de movimento lateral não é suficiente para justificar a salinização.

Cabe pensar que a situação seja diferente, no caso de um poço ou de um grupo de poços. Seja o caso de um grupo de poços, que extraia água numa vazão de $100 \mathrm{l} / \mathrm{s}$. Analogamente, têm-se

$$
\begin{aligned}
s & =\frac{Q}{4 \pi T} W(u), \\
u & =\frac{r^{2} S}{4 \bar{T} t}, \\
W(u) & =\text { função do poço. }
\end{aligned}
$$


No limite:

$$
\begin{aligned}
W(u) & =\frac{0,1 \times 4 \pi \times 50}{86,4 \times 100}=7,27 \times 10^{-3}, \\
u & =3,45, \\
t & =\frac{10^{8} \times 10^{-4}}{4 \times 50 \times 3,45}=1,45 \text { dias, }
\end{aligned}
$$

o que é similar ao caso anterior, tendo, também, sensibilidades similares. Tomando $t=100$ dias, foi extraído $86,4 \times 10^{4} \mathrm{~m}^{3}$.

O deslocamento radial da água é:

$$
\begin{aligned}
& V=\pi r^{2} b m, \\
& r=\frac{86,4 \times 10^{4}}{\pi \times 100 \times 0,1}=166 \mathrm{~m},
\end{aligned}
$$

o que ainda é pequeno para explicar as observaç̃es.

Desse modo, embora o deslocamento horizontal de águas, desde o mar, possa explicar a salinização, o mecanismo se apresenta pouco verossímil.

Considerando-se que a circulação descendente, também, apresenta-se pouco verossímil, em tão pouco tempo, quando o mecanismo é simplesmente o de movimento através de um aquitard homogêneo, e que não se dispõe de informações suficientes com radioisótopos naturais, não é possível estabelecer hipóteses, com suficiente garantia, sobre o processo de salinização, se é que realmente existe. São necessários estudos complementares, orientados especificamente para esclarecer esse problema.

Não deve, porém, ser abandonada a possibilidade de penetração de água salina, ao longo da tubulação, ou a existência de zonas preferenciais de fluxo vertical. Deve-se ter em conta que à relação itb parece assinalar uma certa penetração de águas mais salinas.

SITUAÇÃO POSSÍVEL DA INTERFAGE E DESGARGA DOS AQÜÍFEROS Tal como se acaba de expor, podem ser feitas as conclusões a seguir.

- Os níveis litorais superiores, principalmente o aqüífero Gramame $(\mathrm{Kg})$, estão afetados por uma cunha de intrusão marinha pouco penetrante horizontalmente e limitada em profundidade. A água salgada na zona de maré fica reduzida aos canais e zonas próximas, parecendo ter muito pouca penetração vertical.

- Na parte superior do aqǘfero Beberibe ( $\mathrm{Kb}$ Sup), é provável que a interface com a água do mar esteja pouco afastada lateralmente (horizontalmente), se bem que a incerteza, na piezometria, não permite outras constatações. A descarga de água é efetuada através da Formação Gramame $(\mathrm{Kg})$.

-Na parte inferior do aquífero Beberibe (Kb Inf), a água deve ser quase-estacionária, com a interface teórica muito afastada, porém com uma zona de transição muito espessa, em sentido horizontal. Em condições não-influenciadas, as perdas de água verificam-se através do aqüifero Beberibe superior (Kb Sup), se bem que o fluxo deve ser muito pequeno.

EVOLUÇÃO PROVÁVEL DA SALINIDADE COM UMA INTENSA EXPLOTAÇÃO DOS AQÜIFEROS A conseqüência imediata da intensa explotação dos aqüíferos, que será realizada preferentemente nas faixas média e litorânea, é um decréscimo de níveis piezométricos, com uma inversão dos gradientes verticais, que passarão de ascendentes a descendentes nessas zonas. Cada volume anual de extração, desde que não ultrapasse os recursos da zona, estabelecerá uma situação estacionária de níveis em forma de depressão de bombeamento, que é função da transmissibilidade do aqǘffero e das transferências verticais de água. Os dados existentes, porém parecem mostrar que os decréscimos regionais serão grandes. 
Do ponto de vista da evolução da salinidade da água extraída, não é possível fornecer dados quantitativos, porque são desconhecidos os valores da permeabilidade vertical, a qual pode variar notadamente de um lugar para outro, conforme sejam maior ou menor a freqüência e a espessura de intercalações argilosas.

Considerando-se $K^{\prime}=10^{-3} \mathrm{~m} / \mathrm{dia}$, baseada ainda em poucos dados dos testes de aqüífero, e uma diferença, entre o nível da superfície freática e o do aqüífero profundo, igual a $50 \mathrm{~m}$, a velocidade média do movimento vertical da água será da ordem de $0,5 \mathrm{~m} / \mathrm{ano}$, que é um valor muito pequeno:

$$
v \leqslant \frac{K_{v}}{m} \cdot \frac{s}{b}=\frac{10^{-3}}{0,1} \times \frac{50}{300} \times 360=0,5 \mathrm{~m} / \mathrm{ano}
$$

onde

$$
\begin{aligned}
K_{v} & =\text { permeabilidade vertical } \\
m & =\text { porosidade; } \\
s & =\text { diferença de níveis } \\
b & =\text { espessura } \\
360 & =\text { fator de transformação de dias a anos. }
\end{aligned}
$$

A velocidade de $0,5 \mathrm{~m} /$ ano (velocidade de filtração ou real, e não velocidade de flexo ou de Darcy) é a velocidade de deslocamento de pistão; deve-se supor a dispersão hidrodinâmica macroscópica, da qual não se têm dados e que pode ser elevada. A título puramente orientador, cabe esperar que a curva de $1000 \mathrm{ppm}$ de Cl avance a uma velocidade de 4 a 10 vezes maior, com o que é possível, em situação desfavorável, ao cabo de 50 a 75 anos, iniciar-se um muito lento processo de aumento de $\mathrm{Cl}$.

Isso permite esperar que os poços profundos e bem-cimentados não acusem contaminação salina, nem a curto nem a longo prazos, salvo se existem poços próximos que, por defeitos de construção ou má exploração e conservação, sejam um caminho preferencial para a entrada de águas salgadas. De qualquer modo, é necessária uma gestão comunitária dos recursos de água subterrânea e uma estrita vigilância, com poderes de atuação em casos de necessidade.

É provável que, no transcurso do tempo, a dureza da água aumente, devido ao fluxo descendente de água dura dos níveis superiores, porém isso será também, provavelmente, muito lento e com grande diluição; se a dureza aumentasse com rapidez, com uma paralela anulação da agressividade, até valores similares aos da parte superior do aquífero, seria uma indicação de que a permeabilidade é maior, local ou regionalmente, que o esperado, e nesse caso deveria ser planejada com maior detalhe a questão de penetração de água marinha.

Quanto à parte superior do aqüífero, a proteção é mais deficiente, embora também exista, em especial, próximo do litoral, onde se apresenta recoberto pelo aqüífero Gramame, calcário-margoso. É provável que esses poços, se estão bem construídos, não apresentem problemas de salinização em alguns anos, embora possam aparecer sinais, a médio prazo, nos poços próximos ao litoral ou aos canais de maré interiores. Os problemas aparecem sempre quando se deprime o nível do freático, que atualmente é alto; a vigilância da superfície freática é, pois, muito importante e convém dispor de uma rede de piezômetros apropriada e bem construídos, nos quais se controlem os níveis e a salinidade no perfil.

Se forem evitadas fortes concentrações de bombeamento, é provável que, ainda com uma forte explotação, o aqüífero freático mantenha um nível apropriado somente com a recarga natural anual, já que a infiltração resulta elevada. $O$ saneamento de zonas baixas e as drenagens para construção de edifícios, estruturas, túneis e outras obras civis podem ser especialmente perigosas por deprimirem o nível freático. 
De todo modo, certos problemas locais podem ser resolvidos por recarga artificial, se isso resulta econômico ou necessário, dada a importância de algumas captações. Essa recarga artificial seria, principalmente, para elevar os níveis piezométricos em zonas intermediárias apropriadas.

Todas essas conclusões são baseadas na hipótese de que $K^{\prime}=10^{-3} \mathrm{~m} / \mathrm{dia}$, ou menor, tal como já foi comentado em diversas ocasiões. Não obstante, não deve ser esquecido que existe a possibilidade de valores de $K^{\prime}$ maiores, quer seja homogeneamente ou mediante zonas de circulação vertical preferencial. Nesse caso, cabe esperar que o fenômeno de salinização seja mais rápido, talvez em poucos anos, na faixa litoral, embora, mais para o interior, somente apareçam problemas de maior dureza da água e salinizaçãó locais, perto das zonas de maré.

Só um estudo complementar específico e o ajuste de um modelo de simulação, calibrado com um mínimo de quatro anos de observações hidrométricas completas, podem resolver o problema, com uma aproximação mais satisfatória.

\section{BIBLIOGRAFIA}

BEZERRA, M. A., ALMEIDA, J. C. e SOUZA, P. C. - 1970 - O Aqülfero Beberibe $e$ as Melhores Areas de Captação de Agua Subterrânea. Anais. XXIV Cong. Bras. Geol. pp. 335-348. Brasília BEURLEN, K. - 1967 - Estratigrafia da Faixa Sedimentar Costeira Recife-João Pessoa. Separata do Bol. Soc. Bras. Geol., 16(1), pp. 43-56. São Paulo

CUSTODIO, E. - 1976 - Relaciones Agua Dulce-Agua Salada en las Regiones Costeras. Hidrologia Subterrânea. Ed. E. Custodio, M. R. Llamas. Ediciones Omega, Barcelona, Vol. 2, seccion 13, pp. $1313-1389$

FEITOSA E. G. - 1976 - Reconhecimento Geofisico por Eletrorresistividade da Bacia Sedimentar Costeira $P E / P B / R N$. COMESP (inédito), Recife

MABESOONE, J. M. - 1967 - Sedimentologia da Faixa Costeira Recife - João Pessoa. Bol. Soc: Bras. Geol., 16(1), pp. 57-72

SUDENE, CONESP, OESA - 1976 - Estudos de Reconhecimento e Estudos Hidrogeológicos para Aproveitamento Integrado da Região Centro-Leste da Bacia Potiguar e Bacias Costeiras da Paraíba e Pernambuco. SUDENE (inédito), Recife 